\title{
PERANCANGAN SISTEM PENJUALAN SPARE PART DAN SERVICE PADA BENGKEL KEBUMEN MOTOR
}

\author{
Rosselin$^{1}$, Tri Yani Akhirina ${ }^{2}$, Nurfidah Dwitiyanti ${ }^{3}$ \\ Program Studi Teknik Informatika, Fakultas Teknik dan Ilmu Komputer, \\ Universitas Indraprasta PGRI \\ Jalan Raya Tengah No 80, Kelurahan Gedong, Pasar Rebo, Jakarta Timur \\ rosselinselinsamosir@gmail.com ${ }^{1}$, triyani.akhirina@unindra.ac.id ${ }^{2}$, nurfidah.pulungan@gmail.com ${ }^{3}$
}

\begin{abstract}
Abstrak
Bengkel Kebumen Motor merupakan suatu usaha yang bergerak pada bidang penjualan sparepart dan pelayanan service motor. Bengkel Kebumen Motor menyediakan berbagai perawatan, perbaikan dan penjualan sparepart serta memberikan pelayanan yang optimal bagi pelanggan. Tujuan penelitian ini adalah untuk merancang suatu sistem penjualan sparepart dan service yang dapat mempermudah dalam proses penjualan sparepart dan mengelola data service menjadi lebih cepat, efektif, dan efisien. Metode penelitian yang digunakan dalam perancangan sistem penjualan sparepart dan service pada Bengkel Kebumen Motor yaitu Research and Development (R\&D) dan pengembangan sistemnya menggunakan metode waterfall. Sedangkan dalam teknik pengumpulan data yang digunakan meliputi wawancara, observasi, serta melakukan penelitian kepustakaan yang relevan dengan sistem penjualan sparepart dan service. Hasil dari penelitian ini adalah perancangan sistem terkomputerisasi dibangun dengan menggunakan bahasa pemrograman Java Netbeans dengan menggunakan database MySQL. Dengan menggunakan sistem terkomputerisasi memudahkan karyawan bengkel dalam melakukan pencatatan transaksi, mempermudah pihak bengkel dalam mengetahui jumlah stok sparepart, proses pembuatan laporan dapat dilakukan dengan cepat dan akurat.
\end{abstract}

Kata Kunci :Perancangan Sistem, Penjualan, SparePart, Service, Java

\begin{abstract}
Bengkel Kebumen Motor is a business that is engaged in the sale of spare parts and motorcycle service services. Bengkel Kebumen Motor provides a variety of maintenance, repair and sales of spare parts as well as providing optimal service for customers. The purpose of this study is to design a spare parts and service sales system that can simplify the spare part sales process and manage service data to be faster, more effective, and efficient. The research method used in designing the spare parts and service sales system at the Bengkel Kebumen Motor is Research and Development $(R \& D)$ and the system development uses the waterfall method. Meanwhile, the data collection techniques used include interviews, observations, and conducting library research that is relevant to the spare parts and service sales system. The result of this research is the design of a computerized system built using the Java Netbeans programming language using the MySQL database. By using a computerized system, it makes it easier for workshop employees to record transactions, make it easier for the workshop to find out the amount of spare parts stock, the reporting process can be done quickly and accurately
\end{abstract}

Keywords: System Design, Sales, Spare Parts, Service, Java

\section{PENDAHULUAN}

Perkembangan peranan ilmu pengetahuan dan teknologi yang semakin maju saat ini berpengaruh terhadap kemajuan bisnis usaha, baik secara individual, instansi pemerintah, atau pun swasta. Salah satu bentuk perkembangan teknologi maju adalah komputer. Dengan menggunakan komputer tidak perlu lagi menghitung dan menganalisa data secara manual, selain itu data atau informasi yang diperoleh dari komputer lebih cepat dan akurat dengan perancangan suatu sistem. Perancangan merupakan penggambaran, perencanaan, pembuatan sketsa dari beberapa elemen yang terpisah ke dalam satu kesatuan yang utuh dan berfungsi (Hidayat et al., 2016), sedangkan Sistem adalah kumpulan/group dari sub sistem/bagian/komponen apapun baik fisik atau pun non fisik yang saling berhubungan satu sama lain dan bekerja sama secara harmonis untuk mencapai satu tujuan tertentu (Azhar, 2013). Salah satu jenis usaha dibidang penjualan spare part dan service motor sangat memerlukan adanya sistem pengolahan data untuk mempermudah dan memperlancar kinerja penjualannya, saat ini masih banyak pencatatan data-data penjualan dan service dengan buku dan 
kalkulator, baik itu transaksi ataupun pembuatan laporan sehingga membuat kinerja bengkel menjadi kurang efektif dan efisien, maka dari itu peneliti ingin membuat perancangan sistem penjualan spare part dan service.

Berdasarkan latar belakang di atas, maka rumusan masalahnya adalah bagaimana mengatasi kesulitan dalam mengontrol stok spare part yang ada di bengkel, bagaimana mengatasi kesulitan dalam membuat laporan, bagaimana mengefisienkan proses transaksi penjualan, bagaimana membuat perancangan sistem penjualan yang mampu melakukan proses pencatatan yang masih manual menjadi terkomputerisasi. Manfaat yang didapat dari hasil penelitian ini adalah mempermudah pihak bengkel dalam mengetahui jumlah stok spare part, mempercepat melakukan transaksi penjualan yang dapat digunakan untuk pencatatan transaksi penjualan spare part yang terkomputerisasi, membantu dalam membuat laporan spare part agar lebih efektif dan efisien, menghasilkan sistem yang terkomputerisasi serta memudahkan karyawan bengkel dalam melakukan pencatatan transaksi.

\section{PENELITIAN RELEVAN}

Penelitian relevan merupakan penelitian terdahulu atau sebelumnya yang relevan dengan konsep penelitian sehingga menjadi acuan atau dasar mengembangkan suatu hasil penelitian sebelumnya. Berikut peneliti mengambil sumber dari (Perkasa, 2014) yang berjudul "Perancangan Aplikasi Penjualan Sparepart Pada Bengkel Fajar Motor Menggunakan Metode Berorientasi Objek" dimana dalam jurnalnya sistem penjualan yang dilakukan masih menggunakan cara manual sehingga jaminan keamanan akan tempat penyimpanan data masih sangat rendah, hal tersebut kurang efektif meningkatkan pelayanan. Dilaksanakannya penelitian ini bertujuan untuk merancang suatu sistem informasi berbasis komputer yang dapat membantu perusahaan tersebut dalam mengatur dan mengelola sistem yang ada serta mengatasi permasalahan-permasalahan yang ada dalam perusahaan. Selanjutnya peneliti mengambil sumber dari (Sunoto, 2020) dengan judul "Perancangan Sistem Informasi Jasa Service Dan Penjualan Pada Bengkel Jaya Oil Jambi" hasil penelitian tersebut adalah menawarkan sistem informasi jasa service dan penjualan menggunakan bahasa pemograman PHP dan DBMS MySQL. Dengan adanya sistem baru menghasilkan output yang menampilkan data spare part, data pelanggan, data penjualan dan data service yang secara terstruktur dan menampilkan laporan-laporan yang diperlukan untuk memudahkan Bengkel Jaya Oil Jambi dalam mendapatkan informasi yang cepat dan tepat.

\section{METODE PENELITIAN}

Dalam penelitian ini peneliti menggunakan metode penelitian Research and Development (R\&D). (Sugiyono, 2013) menyatakan bahwa Research and Development (R\&D) adalah metode yang digunakan untuk menghasilkan produk tertentu, dan menguji keefektifan produk tersebut. Sedangkan (Putra, 2012) menyatakan bahwa metode penelitian secara sengaja, sistematis, untuk menemukan, memperbaiki, mengembangkan, menghasilkan, maupun menguji keefektifan produk, model, maupun metode/strategi/cara yang lebih unggul, baru, efektif, efisien, produktif dan bermakna. Dapat disimpulkan bahwa Research and Development (R\&D) adalah suatu teknik atau metode mencari suatu produk, memperoleh, mengumpulkan atau mencatat produk yang digunakan untuk keperluan, dan faktor-faktor yang berhubungan dengan pokok permasalahan sehingga akan didapat suatu kebenaran atas produk yang diperoleh. Dapat juga didefinisikan sebagai metode penelitian yang secara sengaja sistematis, bertujuan, diarahkan untuk mencari/menemukan, merumuskan, memperbaiki, mengembangkan, menghasilkan, menguji keefektifan produk, model, metode/strategi/cara jasa, prosedur tertentu yang lebih unggul, baru, efektif, produktif, dan bermakna. Adapun cara pengumpulan data penelitian ini antara lain :

a. Studi Kepustakaan (Library Research)

Studi pustaka adalah teknik pengumpulan data dengan mengadakan studi penelaah terhadap buku-buku, literatur-literatur, catatan-catatan, dan laporan-laporan yang ada hubungannya dengan masalah yang dipecahkan (Nazir, 2013).

b. Studi Lapangan (Field Research)

Studi lapangan ini lakukan untuk mengamati secara langsung terhadap perancangan sistem penjualan spare part dan service pada Bengkel Kebumen Motor. Dalam studi lapangan ini 
digunakan teknik pengumpulan data observasi yaitu mengamati langsung proses yang berjalan dan wawancara yaitu bertanya langsung kepada pelaksana yang terlibat langsung dalam kegiatan.

Berikut penjabaran tahapan metode waterfall menurut (Pressman, 2012) untuk pengembangan penelitian ini dengan langkah-langkah sebagai berikut :

a. Analisis Data dan Proses (Analysis and Process)

Menganalisa kebutuhan sistem dilakukan pengumpulan dengan berfokus pada perangkat lunak, meliputi : informasi, fungsi masing-masing pada bagian sistem, kerja/cara kerja, antar muka

b. Perancangan (Design)

Pada tahap ini dilaksanakan perancangan struktur data, arsitektur perangkat lunak, rincian prosedural, karakteristik antar muka dilaksanakan pada tahap ini. Dan dirancang tampilan seperti form masukan dan form keluaran dari sistem yang akan dirancang.

c. Pengkodean (Coding)

Pada tahap ini dibuat coding Perancangan Sistem Penjualan spare part dan service pada Bengkel Kebumen Motor yang merupakan tahap untuk membuat suatu kode tentang aplikasi yang akan dibuat agar dapat dibaca dan diterjemahkan oleh komputer.

d. Pengujian (Testing)

Sebelum Perancangan sistem penjualan spare part dan service pada Bengkel Kebumen Motor digunakan dengan baik, harus dilakukan pengujian hal ini dijalankan bersama-sama dengan data aktual dari proses yang sudah ada atau sistem yang sedang berjalan.

e. Pemeliharaan (Maintenance)

Bagian akhir dari siklus dalam Perancangan pada sistem penjualan spare part dan service pada Bengkel Kebumen Motor adalah pada tahap ini dilakukan kegiatan corrective maintenance, yaitu mengoreksi kesalahan pada perangkat lunak yang baru diketahui pada saat perangkat lunak digunakan. Dengan adanya corrective maintenance terhadap aplikasi sistem pengarsipan maka kesalahan-kesalahan yang terdapat pada informasi aplikasi ini dapat diperbaiki.

\section{HASIL DAN PEMBAHASAN}

Data flow diagram atau dalam bahasa Indonesia adalah Diagram Alir Data (DAD) adalah suatu model logika atau proses yang dibuat untuk menggambarkan dari mana asal data dan kemana tujuan data yang keluar dari sistem, dimana data disimpan, proses apa yang menghasilkan data tersebut dan interaksi antara data yang tersimpan dan proses yang dikenakan pada data tersebut Kristanto (dalam Afyenni, 2014). Sedangkan menurut (Sukamto, R. A., \& Shalahudin, 2011) Diagram Alir Data (DAD) adalah representasi grafik yang menggambarkan aliran informasi dan transformasi informasi yang diaplikasikan sebagai data yang mengalir dari masukan (input) dan keluaran (output). Maka dapat disimpulkan diagram alir data (DAD) adalah diagram yang menggambarkan suatu sistem pada aliran informasi dari input dan output yang saling terhubung.

Berikut ini adalah diagram alir data dari diagram konteks sistem berjalan :

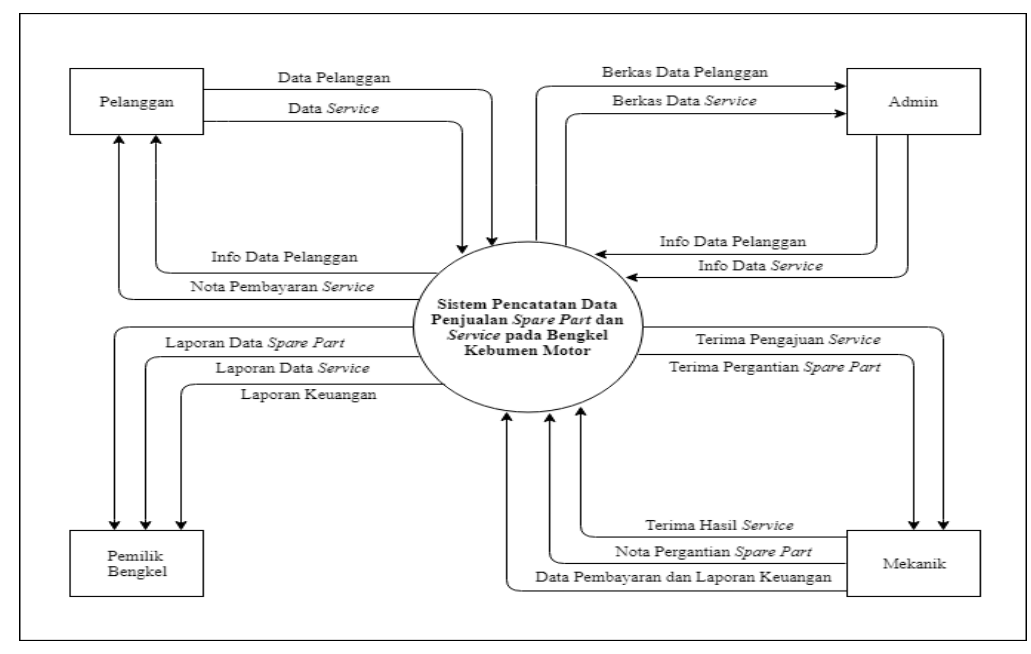

Gambar 1. Diagram Konteks Sistem Berjalan 
Analisis permasalahan yang dapat disimpulkan dari hasil penelitian pada Bengkel Kebumen Motor bahwa bengkel ini masih mengunakan sistem masukan data yang manual, kurang efisien dalam waktu, biaya dan pengerjaan laporan dikarenakan lamanya pencarian data di dalam buku catatan, kesalahan data dalam perhitungan dan pembuatan nota kurang efektif dalam proses transaksi karena semua dibuat dengan manual, data laporan serta informasi yang disajikan kurang lengkap dan akurat. Alternatif penyelesaian masalah yang peneliti usulkan dengan perancangan sistem penjualan spare part dan service yang mendukung proses perhitungan agar proses penjualan dapat dilakukan dengan cepat dan akurat, dapat mengetahui jumlah stok spare part yang tersisa dengan mudah dan cepat, membuat database yang sistematis sehingga memudahkan dalam pencarian data yang dibutuhkan dalam pembuatan laporan, perancangan sistem penjualan spare part dan service pada Bengkel Kebumen Motor dibangun dengan menggunakan bahasa pemrograman Java Netbeans dengan menggunakan database MySQL.

Berikut ini adalah gambaran diagram alir data sistem yang diusulkan pada Bengkel Kebumen Motor adalah sebagai berikut :

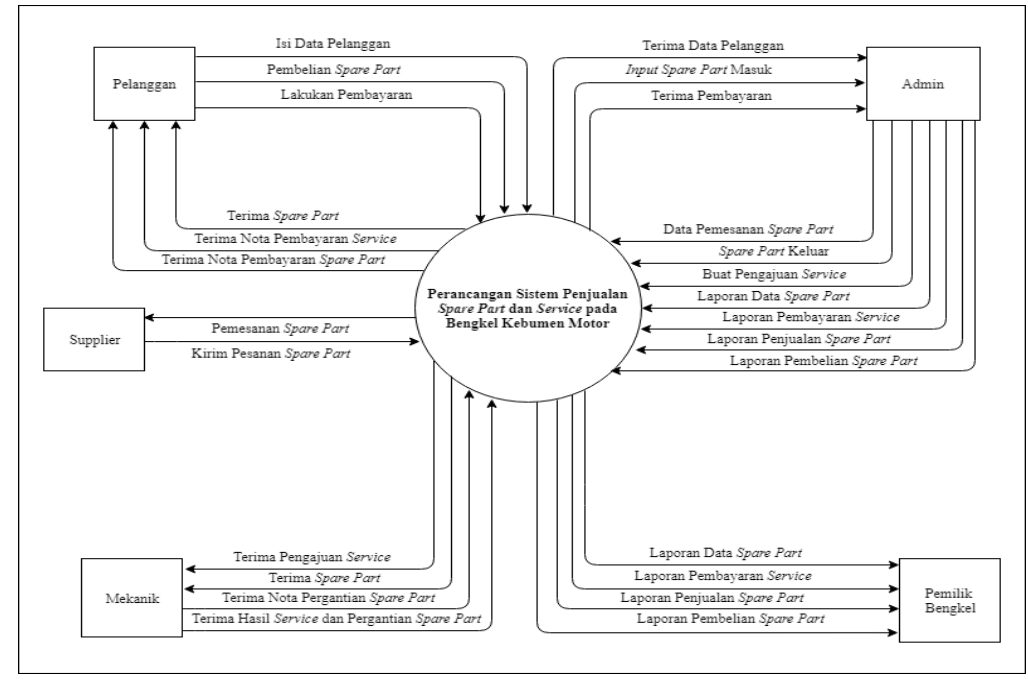

Gambar 2. Diagram Konteks Sistem yang Diusulkan

Pada gambar diatas memperlihatkan gambaran umum dari subsistem rancang bangun sistem penjualan spare part dan service di bengkel kebumen motor. Subsistem aplikasi penjualan spare part dan service, berinteraksi dengan kesatuan luar atau kelompok pengguna yaitu pelanggan, admin, supplier, mekanik, dan pemilik bengkel. Pelanggan memberikan data pelanggan, pembelian spare part dan melakukan pembayaran setelah mendapat layanan service serta menerima nota pembayaran. Admin bisa mengakses semua data pelanggan, spare part, terima pembayaran. Admin juga membuat semua laporan dari sistem penjualan, pembelian, spare part dan service. Selain itu juga admin akan mengecek ketersediaan spare part dan memesan spare part kepada supplier. Mekanik mendapatkan pengajuan service yang diberikan admin, memeriksa motor pelanggan serta memberikan nota hasil service dan pergantian spare part. Pemilik Bengkel dapat melihat seluruh laporan dari sistem penjualan spare part dan service.

Peneliti membuat aplikasi ini dengan menggunakan java netbeans edisi 8.2 dengan database MySQL aplikasi Xampp. Berikut tampilan aplikasi pada Bengkel Kebumen Motor. 


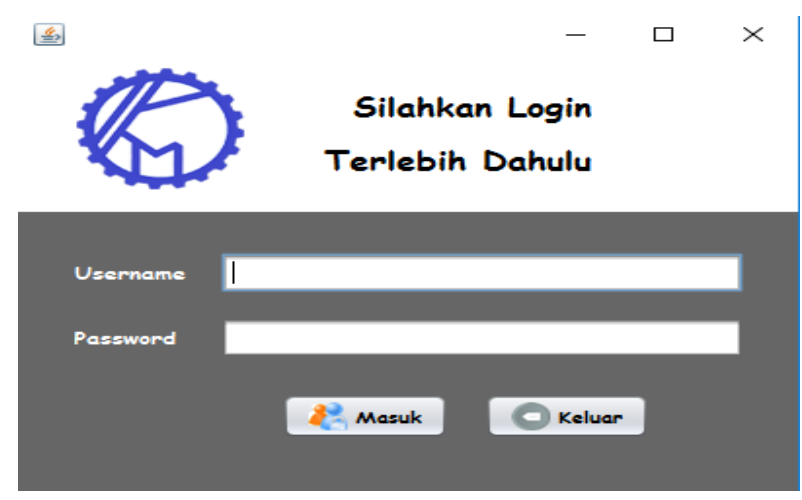

Gambar 3. Tampilan Layar Login

Tampilan layar login terdiri dari menu username, password, masuk dan keluar. Apabila user ingin masuk ke dalam aplikasi, maka harus memasukkan usermane dan password terlebih dahulu kemudian klik tombol masuk.

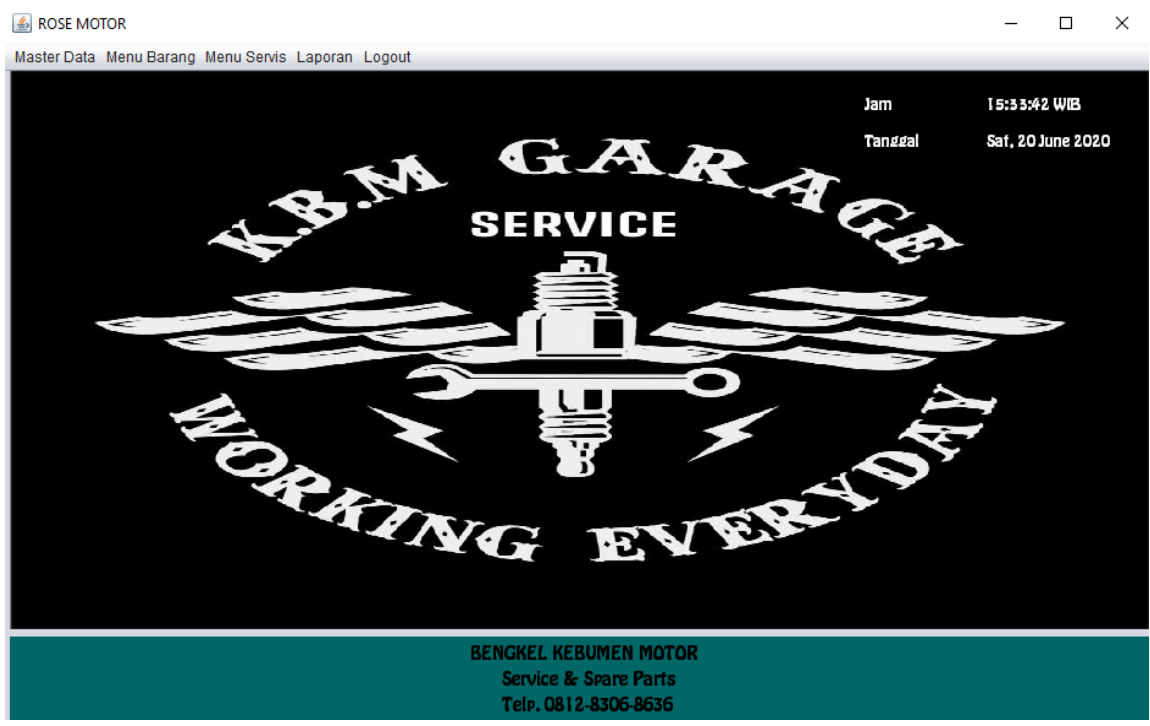

Gambar 4. Tampilan Layar Menu Utama

Jika berhasil login, maka user akan masuk ke menu utama yang terdiri dari :

a. Master Data, dalam menu ini terdiri dari beberapa sub menu, yaitu :

1. Data Spare Part, berisi data stok spare part yang tersedia dan akan dimasukan ke database.

2. Data Montir, berisi data montir yang bekerja dan akan dimasukan ke database.

3. Data Supplier, berisi data supplier yag menjual spare part ke bengkel dan akan dimasukan ke database.

4. Data Pelanggan, berisi data pelanggan yang akan service di bengkel untuk dimasukan ke database.

b. Menu Barang, dalam menu ini terdiri dari dua sub menu, yaitu :

1. Penjualan Barang, berisi data spare part yang akan dijual ke pelanggan.

2. Pembelian Barang, berisi data spare part yang akan dibeli dari supplier.

c. Menu Servis, dalam menu ini terdiri dari dua sub menu yaitu :

1. Pelayanan Servis, berisi data pelanggan yang mengajukan service kendaraan.

2. Pembayaran Servis, berisi data pembayaran yang telah melakukan service kendaraan.

d. Menu Laporan, dalam menu ini terdiri dari beberapa sub menu keluaran, yaitu :

1. Laporan Data Spare Part, berisi rekap data stok spare part yang dapat dicetak.

2. Laporan Pembayaran Servis, berisi rekap pembayaran servis yang dapat dicetak.

3. Laporan Penjualan Spare Part, berisi rekap penjualan spare part yang dapat dicetak.

4. Laporan Pembelian Spare Part, berisi rekap pembelian spare part yang dapat dicetak.

e. Menu Logout, dalam menu ini berfungsi untuk keluar dari aplikasi. 
Berikut ini adalah hasil keluaran (printout) yang nanti hasilnya dapat menjadi laporan manual kepada pemilik bengkel.

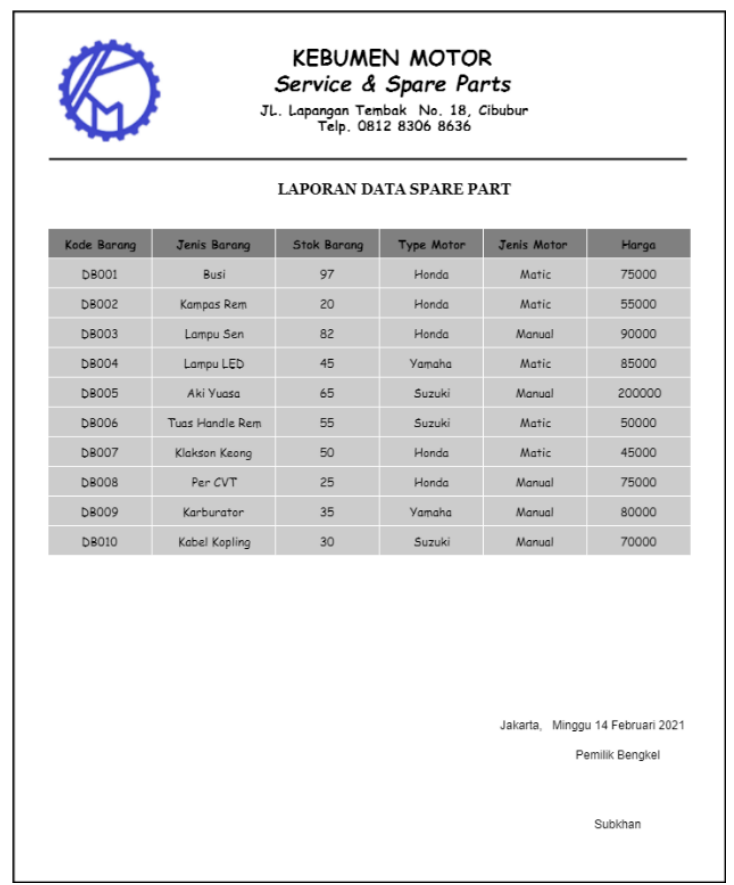

Gambar 5. Tampilan Laporan Data Spare Part

Laporan data spare part ini didapat dari data-data pembelian dan penjualan yang sudah diinput admin ke dalam database yang nantinya diserahkan kepada pemilik bengkel.

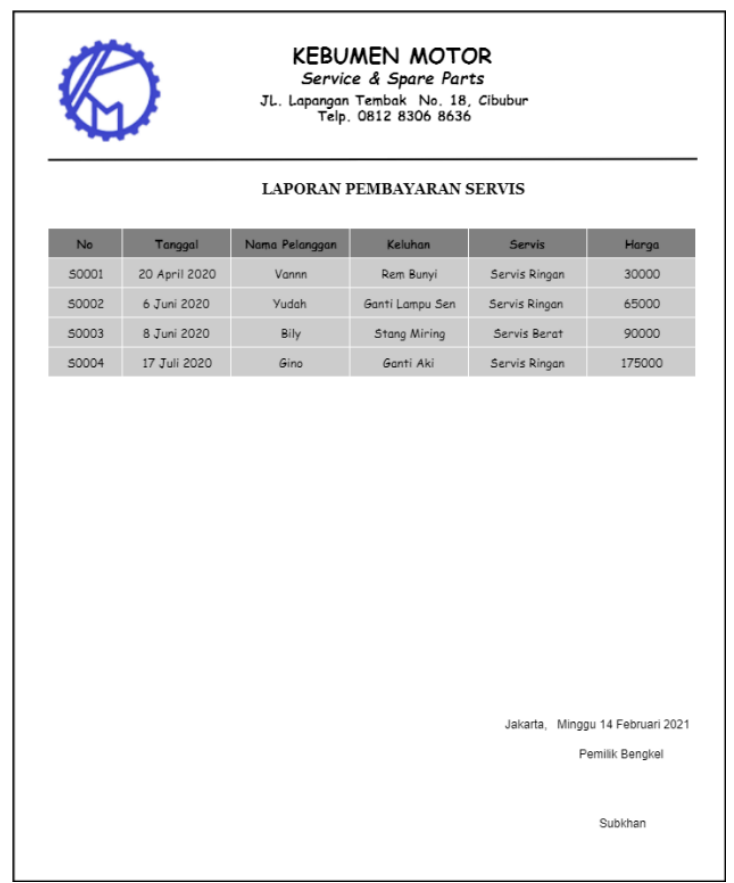

Gambar 6. Tampilan Laporan Pembayaran Servis

Laporan data pembayaran servis ini didapat dari data-data pembayaran servis yang sudah diinput admin ke dalam database yang nantinya diserahkan kepada pemilik bengkel. 


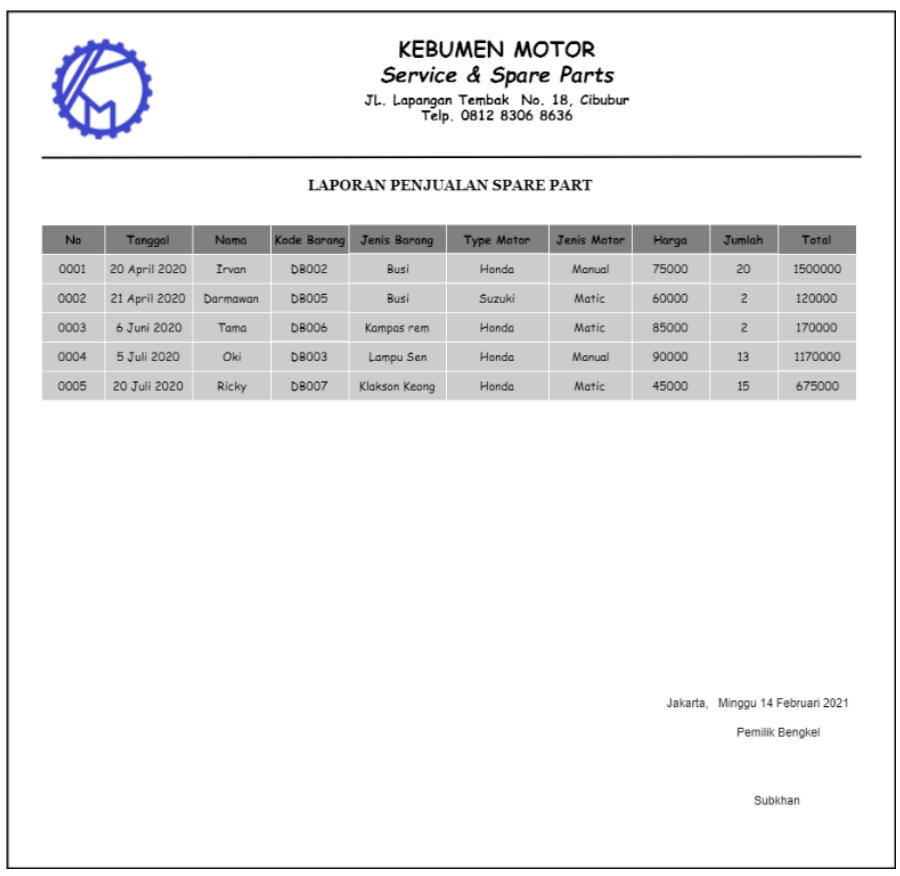

Gambar 7. Tampilan Laporan Penjualan Spare Part

Laporan data penjualan spare part ini didapat dari data-data penjualan yang sudah diinput admin ke dalam database yang nantinya diserahkan kepada pemilik bengkel.

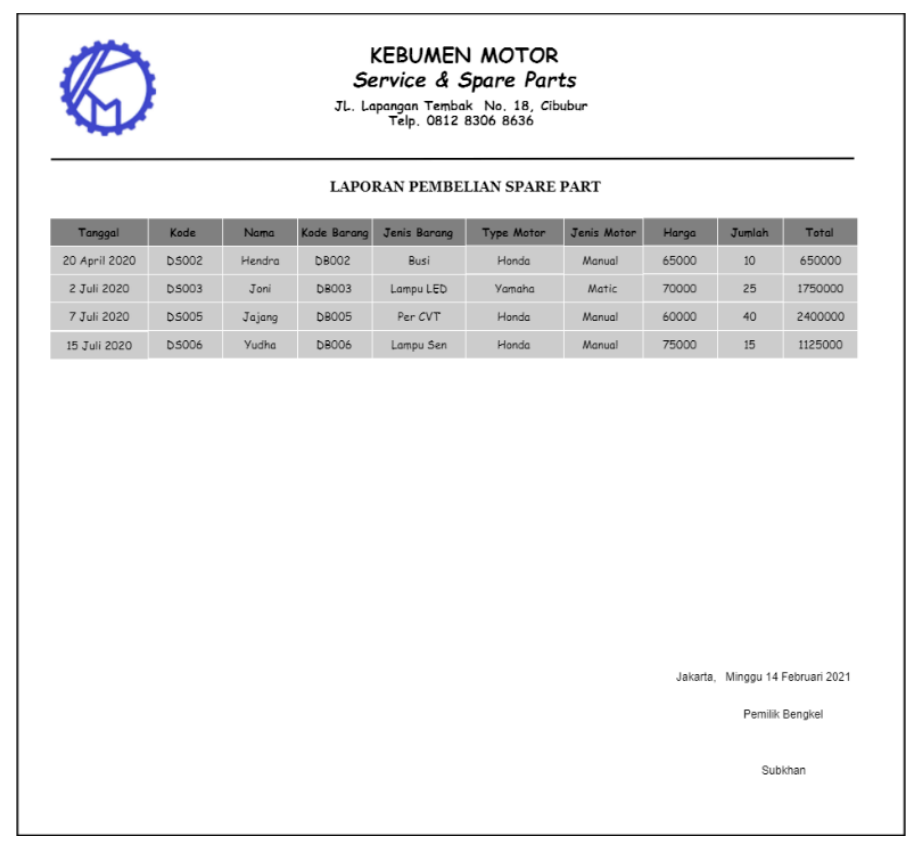

Gambar 8. Tampilan Laporan Pembelian Spare Part

Laporan data pembelian spare part ini didapat dari data-data pembelian yang sudah diinput admin ke dalam database yang nantinya diserahkan kepada pemilik bengkel.

\section{SIMPULAN}

Berdasarkan perancangan sistem penjualan spare part dan service yang telah dibuat oleh penelti untuk memenuhi kebutuhan dan menjawab masalah yang ada pada Bengkel Kebumen Motor, peneliti dapat simpulkan dengan menggunakan sistem komputerisasi maka Bengkel Kebumen Motor dapat mengetahui jumlah stok spare part yang tersisa dengan mudah dan cepat. Hal ini dikarenakan proses pencarian stok dapat dilihat menurut kode spare part. Pengolahan data penjualan spare part 
dan service Bengkel Kebumen Motor lebih efektif serta keamanan terhadap data lebih terjamin serta pembuatan laporan dapat dilakukan dengan cepat dan akurat, memudahkan admin untuk memantau atau mengontrol data yang ada dalam database.

\section{DAFTAR PUSTAKA}

Afyenni, R. (2014). Perancangan Data Flow Diagram Untuk Sistem Informasi Sekolah. In Teknoif (Vol. 2).

Hidayat, W., Maaruf, F., \& Bahari, S. (2016). Perancangan Media Video Desain Interior Sebagai Salah Satu Penunjang Promosi Dan Informasi Di PT. Wans Desain Group. In CERITA (Vol. 2).

Nazir, M. (2013). Metode Penelitian. Ghalia Indonesia.

Perkasa, M. R. (2014). Perancangan Aplikasi Penjualan Sparepart Pada Bengkel Fajar Motor Menggunakan Metode Berorientasi Objek. Jurnal Algoritma, 11(1), 27-33. https://doi.org/10.33364/algoritma/v.11-1.27

Pressman, R. S. (2012). Rekayasa Perangkat Lunak. CV. Andi Offset.

Putra, N. (2012). Research and Development Penelitian dan Pengembangan. PT. RAJAGRAFINDO PERSADA.

Sugiyono. (2013). Metode Penelitian Kuantitatif, Kualitatif dan R\&D. Alfabeta.

Sukamto, R. A., \& Shalahudin, M. (2011). Modul Pembelajaran Rekayasa Perangkat Lunak. Modula Bandung.

Sunoto, A. (2020). Perancangan Sistem Informasi Jasa Service Dan Penjualan Pada Bengkel Jaya Oil Jambi. 2(1), 14-27.

Sutanto, A. (2013). Sistem Informasi Akuntansi. Lingga Jaya. 